\title{
A Different Learning Way For Pupils With Specific Learning Disabilities
}

\author{
FatimaEzzahra Benmarrakchi, Jamal El Kafi, Ali Elhore
}

Dept. of computer science Chouaib Doukkali University, El Jadida, Morocco

\begin{abstract}
Several factors may contribute to a child's failure to learn, some possible causes of school failure are specific learning disabilities. Dyslexia is one of the most common learning disabilities; dyslexia is to fail to learn to read in spite of adequate environment, normal intelligence, and decent educational opportunities. Various studies have recently focused on dyslexia on different scientific areas. Our main focus was to explore the use of Information and Communication Technology (ICT) in education to improve learning for pupils with learning disabilities. In this paper we present a positive approach which considers dyslexia as a different learning style rather than a disability.
\end{abstract}

\section{Indexing terms/Keywords}

Dyslexia, Reading, Specific learning disabilities (SLD), learning styles, Information and Communication Technology (ICT)

\section{Academic Discipline And Sub-Disciplines}

Technology; Education

\section{Council for Innovative Research}

Peer Review Research Publishing System

Journal: INTERNATIONAL JOURNAL OF COMPUTERS \& TECHNOLOGY

Vol. 14 , No. 10

www.ijctonline.com , editorijctonline@gmail.com 


\section{INTRODUCTION}

Reading is a complex cognitive activity, reading competence involves different abilities which are necessary for effective reading comprehension. According to the simple view of reading [1], Reading is understanding on the one hand, and the identification of words written on the other.

Dyslexia or Reading disability is one of the most common learning disabilities. Dyslexia is a disorder manifested by difficulty in learning to read despite conventional instruction, adequate intelligence, and sociocultural opportunity. It is dependent upon fundamental cognitive disabilities which are frequently of constitutional origin [2]. Moreover, dyslexia as a specific type of learning disabilities involving a severe impairment in reading ability which affects and disrupts a person's language development and functioning [3]. Also pupils with dyslexia can actually become confused when several instructions are given at the same time, and will usually have a poor-short-term memory, difficulty with directional orientation, such as telling right from left and map reading [2].

Digital technologies seem to be useful to help pupils with dyslexia to succeed. It may facilitate learning and reduce the difficulties recognizing, or confusing between words and meaning. Multimedia has probably strong positives effects on learning it tends to increase pupil's motivation, confidence and self-esteem.

One possibility is that technology likely to be a key tool in the support of dyslexic pupils. It can be used so as to train, help and even enable the learning process. Specifically designed applications can stimulate student's interest, but, may also help students with disabilities fit into and progress within mainstream school environments [4]. The use of multimedia is also believed to assist dyslexic learners [5]. Multimedia applications do not only allow, but, also support the bimodal presentation of information via visual and auditory channels; thus, information processing is accelerated and mnemonic recall is facilitated [6].

Various studies have recently focused on dyslexia on different scientific areas; the origins of dyslexia, theories of dyslexia the symptoms and diagnosis. However, much less research has been conducted in the potential to use Information and Communication Technology (ICT) to improve teaching and learning for pupils with learning disabilities. To the best of my knowledge, the benefits of using ICT, trough images to transform teaching have not yet been fully explored especially for dyslexic pupils.

Even so, dyslexia is not a sign of low intelligence, or laziness, or even a prediction of failure.

The aim of this study is to present a positive approach, which will probably be used in designing re-education programs, which would focus particularly on the use of visual skills where the picture is the most dominate.

At on purpose, we believe dyslexic brains work differently in all sorts of ways, nonetheless, dyslexic pupils need to learn who matter was the degree of their disabily, due to help them to succeed it may be necessary to give them a different way of teaching.

The remainder of this paper is organized as follows. In Section2, we introduce related work .In Section3, we present our approach of the use of Information and Communication Technology (ICT) in education to improve learning for pupils with learning disabilities. Finally, in Section4 we conclude the paper.

\section{RELATED WORK \\ Dyslexia and Reading}

The psychology of reading has been truly altered by the development of models of reading; however, various researches focus on development of reading process that led to multiple theories which they contribute in the progress of the understanding of developmental dyslexia. Important progress in the understanding of developmental dyslexia in English has come from cognitive modeling of the oral reading system, and verbal models [7] [8] [9] [10].

According to [7] identify a written word involves the use of two models of reading procedures; Lexical reading route or direct pathway and non-lexical reading route or indirect pathway whichever is used in words with low frequently and rare words. The following figures (figure1 and figure 2) show the process of lexical and non-lexical reading routes.

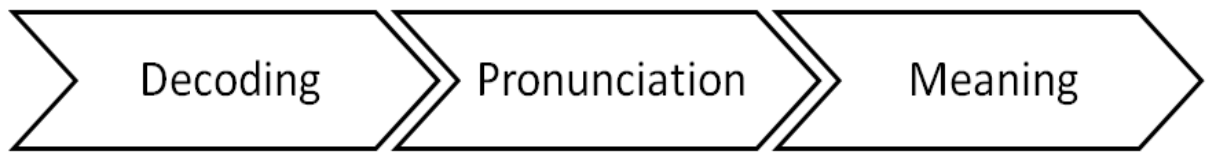

Fig. 1. Lexical reading route [7]

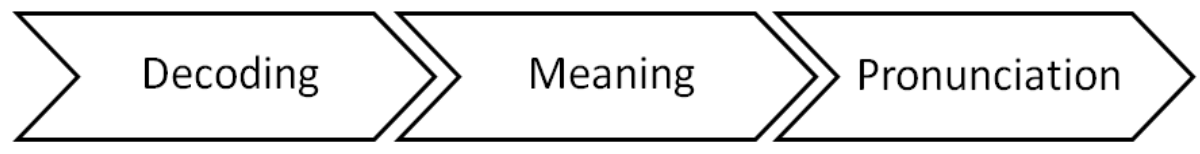

Fig. 2. Non-lexical reading route [7] 
Coltheart et al [8] proposed a "multi-route" model of oral reading in English that admits there is an available lexical semantic pathway for reading aloud all known words just as a direct lexical pathway that can read words aloud without contacting the meaning of the word itself, figure 3 shows the process of dual route model.

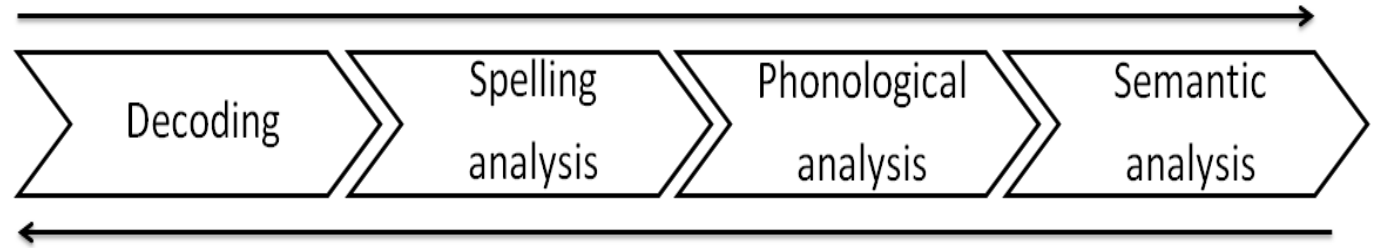

Fig. 3. Dual route [8]

Plaut et al. suggested another model that also admits semantic and orthography to phonology pathways are available for normal reading in English; however, this model is based on connectionist principles of subsymbolic processing [9].

Seidenberg et McClelland [10] introduced a connectionist model of reading word, the model presume to read words three codes are included; orthographic, phonological and semantic. Each code corresponds to an activation distributed on a set of elementary units; in each unit different activation patterns allow to encode different codes. This model proposes an interactive processing; it suggests the existence of hidden units between orthographic levels, phonological and semantic, that increase the network processing capabilities, which is represented in the figure 4 below.

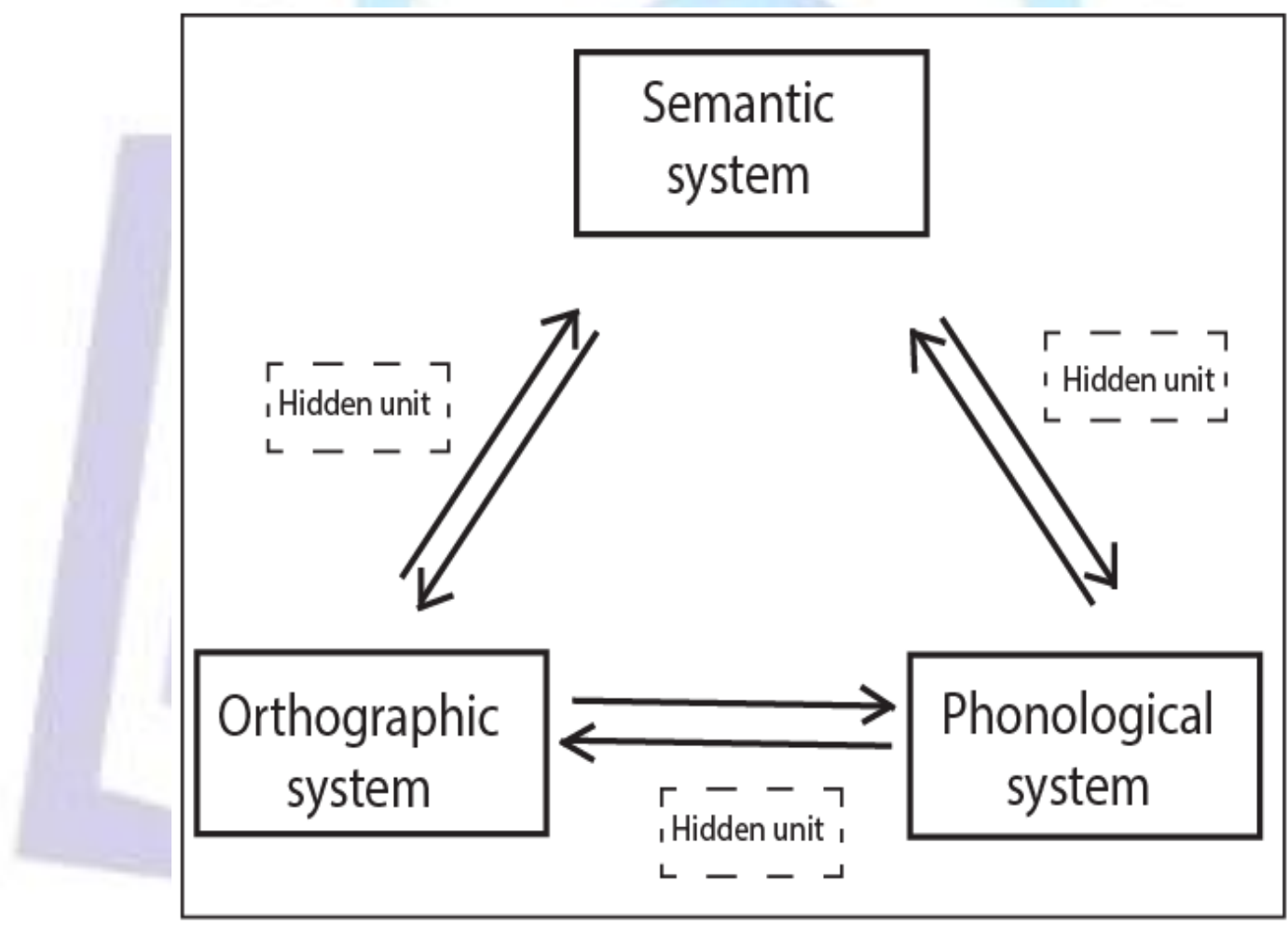

Fig. 4. Connectionist model [10]

In English acquired surface dyslexia refers to impairment in the reading aloud of irregular words, especially when the words are low frequency, rare and abstract in meaning with a spared ability to read regular words and nonwords. Pupils with surface dyslexia make errors at the subword level when they are reading irregular words, in the same way as Chinese individuals when they are learning to read characters. Besides, individuals with acquired phonological dyslexia represent impairment when they are reading aloud nonwords with a spared ability to read aloud irregular words and regular words. Further individuals with acquired deep dyslexia produce semantic errors when they are reading words aloud, more specifically when the word is abstract. Indeed the cases of acquired phonological, surface and deep dyslexia have been reported in many languages among other French, Italian, Spanish, Dutch, and Japanese.

Figure 5 displays the lexical model processing in Chinese, The model considers the lexical semantic and a nonsemantic pathway are functionally independent, then can be selectively impaired or else develop at different rates in beginning readers. The pathways are linked via a set of bi-directional connections allowing feed-forward and feedback connections between orthographic and phonological representations. 


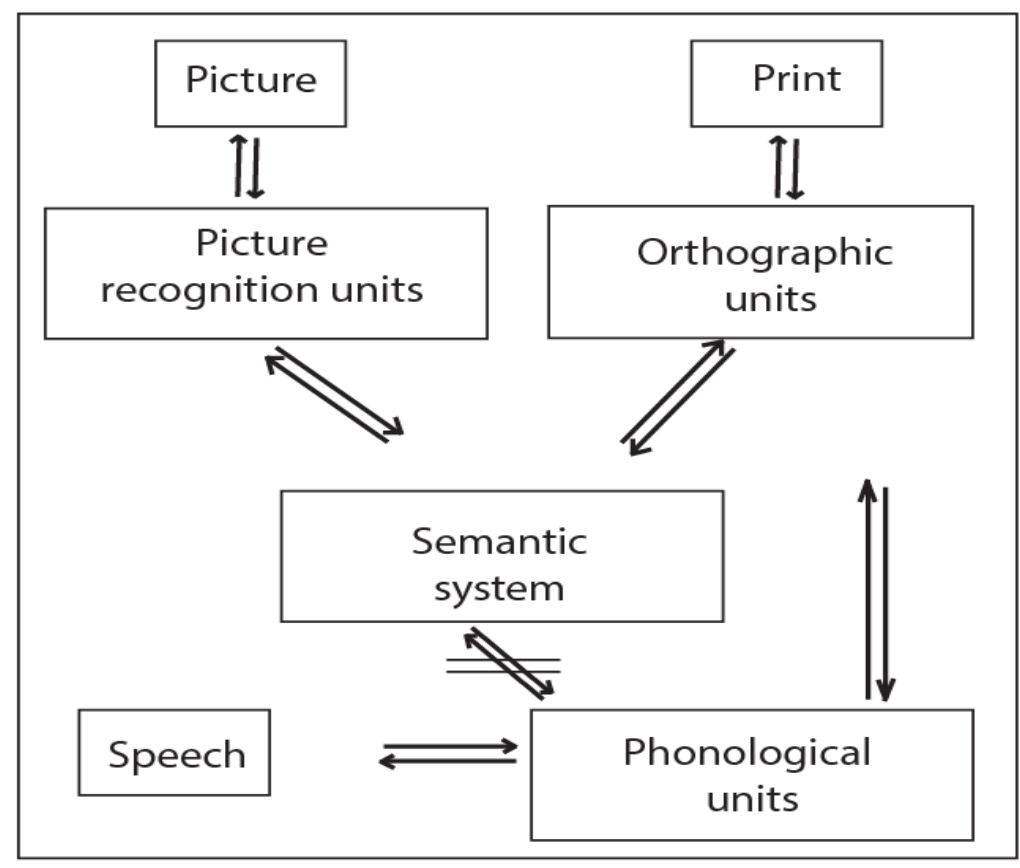

Fig. 5. Lexical model processing in Chinese [11]

\section{Dyslexia and ICT}

Dyslexia is a hidden disability in varying degrees, which affects relatively about $7-10 \%$ of the population across most languages and cultures [12].

Some Research has been conducted to improve the benefits of the use of Information and Communication Technology in education and learning, that can help and motivate pupils especially pupils with learning disabilities.

It appears that digital technologies might help pupils with specific learning disabilities, Thomas regarded ICT (Information Communication Technology) as an enabler, as it can facilitate access to students by learning, increasing their motivation, fostering self-competition, enhancing their confidence and self-esteem [13]. Several studies have been focused on this area. For instance the use of websites as an educational motivators for adults with learning disabilities [14], virtual environments [15] [16], and computer games [17] [18].

The pedagogical characteristics of the ICT make the technology as powerful and supporting tool in education [19]. ICT promote collaboration and communication by means many activities including the collection, processing, storage and representation of data and information [20].

In addition, MyLexics is an interactive multimedia program that supports children with learning disabilities. It is a courseware that integrates all multimedia elements that reinforces interactive and self-learning environment for dyslexic pupils. According to Brown [21], MyLexics content has been structured as building-up process, where the children initially learn the individual alphabets and then combine the alphabets to other syllables, before finally they add the combined syllables to other syllables and form words.

Besides, Easylexia [22] is a mobile application for children with special learning needs, it provides a learning environment which foster learning and help children with their learning difficulties by improving some of their elementary skills, such as language and mathematical abilities.

It is possible to see that the ICT is a key tool in the support of dyslexic pupils. In 2002 Anita Keates [23] consider that ICT is an area where what is possible to support and facilitate dyslexic students. She reported that dyslexic students use ICT because it is an area where they generally have not previously failed. It is helpful, supportive, facilitating and motivating. In her research, Anita Keates has proven that dyslexic children have skills in keyboarding, handling mouse, and interact with the screen.

\section{OUR APPROACH}

Usually dyslexic pupils lack distributed automatic processing of languages, and this can be explained by, the use of their frontal strategic parts of the brain [24]. Over the past years, functional imaging studies have made important advances in identifying the neural basis of word reading in developmental dyslexia. Largely, dyslexic participants have been reported to show a pattern of differential activation relative to normal readers that have clustered in three key left hemisphere regions, a set of left frontal regions largely centered on the inferior frontal gyrus; the left temporoparietal region, including the supramarginal gyrus and the posterior aspect of the superior temporal gyrus (Wernicke's area); and the left posterior inferior temporal lobe (BA 37), now more commonly referred to as the occipitotemporal region [25]. 
Howard Gardner [26] proposed a new theory and definition of intelligence in his book Frames of Mind: The Theory of Multiple Intelligences. The theory of multiple intelligences is a theory of intelligence that differentiates it into specific modalities or primarily sensory rather than seeing intelligence as dominated by a single general ability.

According to Gardner's Theory of Multiple Intelligences, each human being is capable of various forms of intelligence relatively independent forms of information processing, with individuals differing from one another in the specific profile of intelligences that they exhibit.

Relatively dyslexic individual has general skills disproportionately better than reading skills; He is often creative and innovative especially in his thought and planning processes, in consequence of his often dominant right hemisphere, He has strong visual skills, and it appears that dyslexic individual has high visual-spatial intelligence which is the ability to perceive and create mental images.

Dyslexic individual has often difficulties with letters and their orthographic and phonological representation. He has difficulties affecting the acquisition of reading skills,that achieve lower levels of reading efficiency although he had normal education guidance and have adequate intelligence, Conforming to Rudolf Berlin [24], dyslexia means "difficulty with words" [27] [28],

Appropriately it may be beneficial to consider dyslexia as an alternative learning style rather than a disability. Until this point dyslexic individual learning style seems likely different, probably because he thinks using images and shapes in three dimensions, Adopting technological tools in learning may have the qualities of being a key tool in the support of dyslexic pupils.

For our present purpose, it is useful to offer a new virtual and attractive environment to dyslexic individual, seeing that they might need a different way to process the information. In this virtual environment the image will be the most dominant. It possible to see that through the ICT, images might be easily used in teaching and improving the retentive memory and ensure comprehension of dyslexic pupils.

This new learning approach will focus on pictures symbols and shapes, dyslexic pupils will probably understand better if a text consists of pictures. And by adding spoken encouraging comments (feedbacks) the learning would be possibly more enjoyable over this virtual environment side, which could improve pupil's attendance and concentration, and also might inspire deep reflective thinking. Moreover, it can increase confidence, success and self-esteem.

Understanding the disability will presumably lead us to change the way that we think about dyslexia and learning differences. In this way we hope we can offer to dyslexic pupils the appropriate learning style that they need and that seems suitable for this purpose.

\section{CONCLUSIONS AND FUTURE WORK}

Exploring the use of Information and Communication Technology (ICT) in education to promote learning for pupils with learning disabilities, we primarily focused on introducing a positive approach which is directed at improving pupil's learning skills through the use of images. In our ongoing work the approach will be developed in a virtual environment in three dimensions, in order to study its effectiveness on learning performances. The aim is to evaluate its usability on dyslexic pupils.

\section{REFERENCES}

[1] Hoover, W.A., \& Gough, P.B. (1990). The simple view of reading. Reading and Writing, 2, 127-160.

[2] Alwell, M.,\& Cobb, B..(2009).functional Life Skills Curricular Interventions For Youth With Disabilities. Career Development For Exceptional Individuals,32(2):82-93

[3] Blustein, D.L. (2006). The Psychology Of Working: A New Perspective For Career Development, Counselling, And Public Policy. London: Lawrence Erlbaum, p.p, 1-57

[4] P. Williams, H. R. Jamali, and D. Nicholas, "Using ICT with people with special education needs: what the literature tells us," Aslib Proceedings, vol. 58, no. 4, pp. 330-345, Jan. 2006.

[5] R. S. Fadilahwati Abdul Rahman, Fattawi Mokhtar, Nor Aziah Alias, Multimedia Elements as Instructions for Dyslexic Children, International Journal Of Education And Information Technologies, vol. 6, no. 2, 2012.

[6] T. A. Kazakou, M., Soulis, S., Morfidi, E., Mikropoulos, "Phonological Awareness Software for Dyslexic Children," Themes in Science and Technology Education, vol. 1, no. 4, pp. 35-54, 2011.

[7] Coltheart, M., Curtis, B., Atkins, P., \& Haller, M. (1993). Models of reading aloud: Dual-route and parallel-distributedprocessing approaches. Psychological Review, 100(4), 589-608.

[8] Coltheart, M., Rastle, K., Perry, C., Langdon, R., \& Ziegler, J. C. (2001). DRC: a dual route cascaded model of visual word recognition and reading aloud. Psychological Review, 108(1), 204-256.

[9] Plaut, D. C., McClelland, J. L., Seidenberg, M. S., \& Patterson, K. (1996). Understanding normal and impaired word reading: Computational principles in quasi-regular domains. Psychological Review, 103 (1), 56-115.

[10] Seidenberg, M. S., \& McClelland, J. L. (1989). A distributed, developmental model of word recognition and naming. Psychological Review, 96(4), 523-568. 


\section{ISSN 2277-3061}

[11] Weekes, B. S., Chen, M. J., \& Yin, W. G. (1997a). Anomia without dyslexia in Chinese.Neurocase, 3, 51-60.

[12] Peterson, R.L., \& Pennington, B.F. (2012) Developmental Dyslexia. Lancet. 379. 1997-2007. DOI: 10.1016 S01406736(12)60198-6.

[13] M. Thomas, I.T. and Students with Emotional and Behavioural Difficulties. Coventry: National Council for Educational Technology.

[14] R. Johnson and J. R. Hegarty, Websites as educational motivators for adults with learning disability, British Journal of Educational Technology, vol. 34, no. 4, pp. 479-486, Sep. 2003.

[15] B. M. Brooks, F. D. Rose, E. A. Attree, and A. Elliot-Square, "An evaluation of the efficacy of training people with learning disabilities in a virtual environment.," Disability and rehabilitation, vol. 24, no. 11-12, pp. 622-6.

[16] F. D. Rose, B. M. Brooks, and E. A. Attree, An exploratory investigation into the usability and usefulness of training people with learning disabilities in a virtual environment.

[17] T. A. Kazakou, M., Soulis, S., Morfidi, E., Mikropoulos, "Phonological Awareness Software for Dyslexic Children," Themes in Science and Technology Education, vol. 1, no. 4, pp. 35-54, 2011.

[18] J. Larcher, "Information technology for children with language difficulties," in in Difficulties in an Educational Context, W. Rinaldi, Ed.Whurr Publishers Ltd, 2000.

[19] Jonassen DH. Computers as mindtools for schools: Engaging critical thinking. New Jersey: Prentice Hall Inc.;1999.

[20] Mikropoulos TA, Natsis A. Educational virtual environments: A ten-year review of empirical research (1999-2009). Computers \&Education 2011;56:769-780.

[21] Brown, B.,(2002). Generic Skills in Career And Technical education (Report no.22).Columbus,OH: Center on Education nad training for Employment.(Eric Document Reproduction service no.ED472363)

[22] R. Skiada, E. Soroniati, A. Gardeli, et D. Zissis, “ EasyLexia: A Mobile Application for Children with Learning Difficulties », Procedia Comput. Sci., vol. 27, p. 218-228, 2014.

[23] A. Keates, Dyslexia and Information and Communications Technology: A Guide for Teachers and Parents. 2002.

[24] Shaywitz, S., Shaywitz, B., Pugh, K., Fulbright, R., Constable, R., Mencl, W., Shankweiler, D., Liberman, A., Skudlarski, P., Fletcher, J.,Katz, L., Marchione, K., Lacadie, C., Gatenby, C. and Gore, J. 1998. Functional disruption in the organization of the brain for reading in dyslexia. Proceedings of the National Academy of Sciences, 95 (5), pp. 2636-2641.

[25] Habib, M. (2000). The neurological basis of developmental dyslexia: an overview and working hypothesis. Brain, 123 , 2373-2399.

[26] Gardner, H. (1983). Frames of mind: The theory of multiple intelligences.

[27] Berninger VW, Nielsen KH, Abbott RD, Wijsman E, Raskind W. Writing Problems in Developmental Dyslexia: UnderRecognized and Under-Treated. J Sch Psychol 2008;46:1-21.

[28] Ott P. How to Detect and Manage Dyslexia. A Reference and Resource Manual. UK: Heinemann Educational Publishers; 1997. 